\title{
Cursing \\ BIRTHING BALL EXERCISE FOR PROMOTION OF NORMAL BIRTH AMONG GNM NURSING STUDENTS
}

\section{Ms. Geetanjali Singh* \\ Dr. Mansi Choudhary

M.Sc. Nursing Final Year, Obstetric \& Gynecological Nursing, SAIMS College Of Nursing, Indore. (M.P) *Corresponding Author

Associate Professor, Obstetric \& Gynecological Nursing, SAIMS College Of Nursing, Indore. (M.P) became delivered as a childbirth tool in 1980 through Perez and Simkin, Perez in 2001 said that the birthing ball turned into physically beneficial use in the course of pregnancy and labor by means of generating most advantageous positioning and pain discount at some stage in contraction whilst eliciting non-recurring motion. The size of population included this study was 80 GNM Nursing Final year students which were selected according to inclusive and exclusive criteria. The mean difference of 9.03 points in knowledge scoring between pretest $(7.65 \pm 1.21)$ and post-test $(16.68 \pm 1.41)$ was statistically strongly significant $(\mathrm{p}<0.001)$. This is clearly reflected that the planned teaching programme regarding birthing ball exercise for promotion of normal birth of GNM Nursing final year students found to be effective in improving knowledge about birthing ball exercise for promotion of normal birth.

\section{KEYWORDS : Planned Teaching Programme, GNM Nursing Final Year Students, Birthing Ball Exercise, Promotion Of} Normal Birth.

\section{INTRODUCTION}

Birth ball has been introduced to the obstetric setting to facilitate the mobilization of the laboring women and nowadays birth ball has become more popular in many hospitals and birth centers. Swaying movements increase more benefits to the mothers. The sitting position assumed on the ball, similar to a squat, opens the pelvis, helping to speed up labour and gently moving on the ball greatly reduces the pain of contractions 10 With the ball on the floor or bed, the mother can kneel and lean over the ball, encouraging pelvic motion which can aid a posterior baby in turning to the correct position, thus allowing labour to progress more quickly. This position is wonderful for a mother who is having back labour caused by a posterior position.

Although various position and movements adopted during labour, controversy still exit to Choose the best. Additionally, in developed countries many hospitals today provide amenities like birth ball, rocking chair, beanbags, tubs or showers, in birth suite in order to make women stay out of bed and enhance the sense satisfaction. But in developing countries like India these options are lacking in birth centers.

\section{OBJECTIVES}

1. To assess the pre-test knowledge regarding birthing ball exercise for promotion of normal birth among GNM Nursing Final year students.

2. To evaluate the effectiveness of planned teaching programme on knowledge regarding birthing ball exercise for promotion of normal birth, among GNM Nursing Final year students.

3. To find out the association between pre-test knowledge regarding birthing ball exercise for promotion of normal birth, among GNM Nursing Final year students.

4. To find out the association between post-test knowledge score regarding birthing ball exercise for promotion of normal birth, among GNM Nursing Final year students with their selected demographic variable.

\section{HYPOTHESIS}

1. $\mathbf{R H}_{0}$ : There will be no significance difference between pre-test and post-test knowledge score regarding birthing ball exercise for promotion of normal birth, among GNM Nursing Final year students.

2. $\mathbf{R H}_{\mathbf{1}}$ : There will be significant difference between pre-test and post-test knowledge score regarding birthing ball exercise for promotion of normal birth, among GNM Nursing Final year students.

3. $\mathbf{R H}_{2}$ : There will be significant association between pre-test and post-test of knowledge regarding birthing ball exercise for promotion of normal birth, among GNM Nursing Final year students.

\section{METHODOLOGY}

In this study pre- experimental one group pre-test post-test research design was used in the study. The samples were recruited by nonprobability convenient sampling technique. The size of population included this study was 80 GNM Nursing Final year Students which were selected according to inclusive and exclusive criteria. They were given a planned teaching programme to give their response to assess the knowledge regarding birthing ball exercise for promotion of normal birth.

\section{RESULT}

- According to age major part $(65,81.3 \%)$ of population of GNM Nursing final year students was more frequently belonged to the lower age group of 20-23 years.

- Genders of GNM Nursing final year students revealed that most of the studied $(55,68.7 \%)$ of population of GNM Nursing final year students found to be female.

- Marital status of GNM Nursing final year students revealed that birthing exercise for $(80,100.0 \%)$ the studied population of GNM Nursing final year students found to be unmarried.

- Analysis about previous knowledge of GNM Nursing final year students about birthing ball exercise for promotion of normal birth indicated that less than $3 / 4(70.0 \%)$ of the GNM Nursing final year students didn't have any previous knowledge about birthing ball exercise for promotion of normal birth.

Table No. I Frequency and percentage distribution of selected GNM Nursing final year students. $(\mathrm{N}=\mathbf{8 0})$

\begin{tabular}{|c|c|c|}
\hline Characteristics of Sample & Frequency $(\mathbf{N})$ & Percent (\%) \\
\hline \multicolumn{3}{|c|}{ Age of GNM Nursing final year students } \\
\hline 20-23 year & 65 & 81.3 \\
\hline $24-27$ year & 15 & 18.7 \\
\hline 28-31 year & 0 & 0.0 \\
\hline$>31$ and $<35$ years & 0 & 0.0 \\
\hline \multicolumn{3}{|c|}{ Gender of GNM Nursing Final Year students } \\
\hline Male & 25 & 31.3 \\
\hline Female & 55 & 68.7 \\
\hline \multicolumn{3}{|c|}{ Marital status of GNM Nursing Final Year Students } \\
\hline Married & 0 & 0 \\
\hline Unmarried & 80 & 100.0 \\
\hline \multicolumn{3}{|c|}{ Previous knowledge of GNM Nursing final year students } \\
\hline No & 56 & 70.0 \\
\hline Yes & 24 & 30.0 \\
\hline \multicolumn{3}{|c|}{ Source of previous knowledge of GNM nursing final year student } \\
\hline None & 56 & 70.0 \\
\hline Conference & 11 & 13.8 \\
\hline Seminar & 12 & 15.0 \\
\hline Newspaper & 1 & 01.2 \\
\hline Total & 80 & 100.0 \\
\hline
\end{tabular}


Comparison of pre- test and post- test knowledge score regarding birthing ball exercise for promotion of normal birth among GNM Nursing final year students. $(\mathrm{N}=80)$

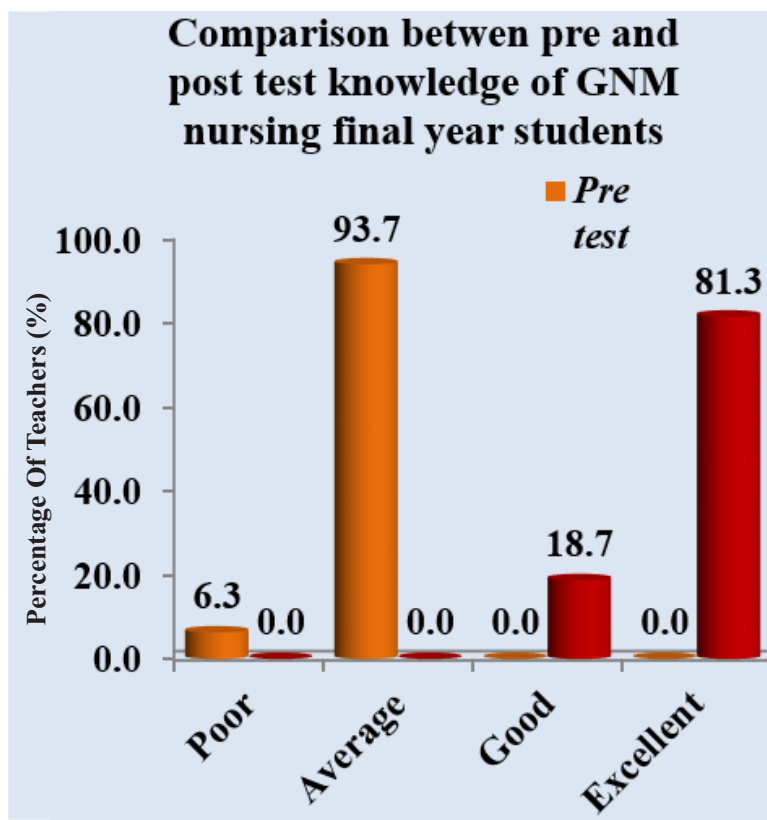

Figure I- Bar diagram showing the comparison in knowledge levels among GNM Nursing final year students before (pre-test) and after administration (post-test) of planned teaching programme.

The mean difference of 9.03 points in knowledge scoring between pretest $(7.65 \pm 1.21)$ and post-test (16.68 \pm 1.41$)$ was statistically strongly significant $(p<0.001)$. This is clearly reflected that the planned teaching programme regarding birthing ball exercise for promotion of normal birth of GNM Nursing final year students found to be effective in improving knowledge about birthing ball exercise for promotion of normal birth.

\section{CONCLUSION}

There was a gain of $118.04 \%$ in knowledge about birthing ball exercise for promotion of normal birth among GNM Nursing Final year students. Overall, the planned teaching programme knowledge consider as an effective tool when there is a need in lacking, bridging and modifying the information about birthing ball exercise for promotion of normal birth. There was a change noticed in knowledge score at post-test stage found to be higher after administration of planned teaching programme on knowledge and the knowledge score rose to ( $16.68 \pm 1.41$ points).

The null hypothesis was rejected and consequently the alternate hypothesis being accepted. Finally, this was concluded that there was a significant difference between pre-test and post-test knowledge scoring regarding birthing ball exercise for promotion of normal birth among GNM Nursing final year students.

Lastly these statistical findings concluded the effectiveness of planned teaching programme on knowledge regarding birthing ball exercise for promotion of normal birth among GNM Nursing Final year students which confirm the objectivity of the present research study.

Association of knowledge of birthing ball exercise for promotion of normal birth among GNM Nursing final year students with their selected demographic variables. In pre-test all the demographic variables i.e. age, gender, marital status, and previous knowledge about birthing ball exercise for promotion of normal birth was statistically non-significant at $\mathrm{p}>0.05$ and after administration of planned teaching programme the demographic variable post-test i.e. age, gender, and previous knowledge about birthing ball exercise for promotion of normal birth were found to be statistically significant at $\mathrm{p}<0.05$ and marital status was found to non-significant.

REFERENCES

1. Janet Balaskas, "Preparing for natural birth", publishers an imprint of Harper Collins. Janet Balaskas,
Page no. 34-36.

2. John Studd, "Current progress in obstetrics and gynecology", 2nd edition (2014), published by Suketu P. Kothari medical subscription services Pvt. Ltd. Page no. 79-81. 3. Kitzinger Sheila, "The complete book of pregnancy and child birth", published by Alfred A. Knopf, New York. Page no. 11-15.

4. Kothari C.R., "Research Methodology", 2nd edition (2006), New Delhi: New age international (p) Ltd publishers. Page no. 198-224.

5. Gau ML, et.al Effects of birth ball exercise on pain and self-efficacy during childbirth: randomized controlled trial in Taiwan. Journal of Midwifery. 2011; 27(6):e293-e300. Doi: 10.1016/j.midw.2011.02.004.

6. Geetha C R., Pregnancy and childbirth, Journal of Midwifery Nursing.2013 June 7 : 3): $15-17$

7. Mahtab Attarha. Effectiveness of the birthing ball technique in the progress of the labor duration. Available from:URL:http://www.lib.bioinfo.pl/pmid

8. Makvandi S, et.al Effect of birth ball on labor pain relief: A systematic review and Meta-analysis. Journal of Obstetrics \& Gynecology Res. 2015; 41(11):1679-86. Doi: 10.1111/jog. 12802

9. Perez P. Birth balls: use of physical therapy balls in maternity care. East Johnson, Journal of Obstetrics \& Gynecology, VT: Cutting Edge Press; 2000

10. Rose Mary Nieswiadomy. Effectiveness of birthing ball exercise in the intrapartum period. Availablefrom:URL:http://www.ecam oxfordjournals.org

11. SC Winny, et.al The birth ball experience: Outcome evaluation of the intrapartum use of birth ball. Hong Kong J gynecologist midwifery 2011

12. Shallow H. My rolling programme- the birthing ball ten years of experience of using the physiotherapy ball for laboring women. Midrise Midwifery digest2003: 13;28-13

13. Sukumaran S. A study on effect of birthing ball in reduction of labor pain among primigravida mothers. PG dissertation. Nitte University. Mangalore: 2015

14. Vaijayanthimala M., et.al Effectiveness of Birth ball Usage during Labor on Pain and Child Birth Experience among Primi Parturient Mothers: A Randomized Interventional Study international journal of scientific research. 2014;33(7): 416-18.

15. Watkins SS. Get on the ball - the "birth ball" that is! International Journal of Childbirth education 2001; $16: 17-19$ 